\title{
Classification and comparison of snow fences for the protection of transport infrastructures
}

\author{
Luis A. Sañudo-Fontaneda ${ }^{1 *}$, Daniel Castro-Fresno ${ }^{2}$, J.J. del Coz-Díaz ${ }^{3}$, Jorge \\ Rodriguez-Hernandez ${ }^{4}$
}

${ }^{1} \mathrm{PhD}$. Student, Dept. of Transport, Project and Process Technology, ETSICCP, University of Cantabria, 39005 Santander, Spain. E-mail: sanudola@unican.es

${ }^{2}$ Professor, Dept. of Transport, Project and Process Technology, ETSICCP, University of Cantabria, 39005 Santander, Spain. E-mail: castrod@unican.es

${ }^{3}$ Professor, Dept. of Construction, EPSIG, University of Oviedo, Departmental Building 7,33204 Gijón, Spain.E-mail: juanjo@constru.uniovi.es

${ }^{4}$ Assistant Professor, Dept. of Transport, Project and Process Technology, ETSICCP, University of Cantabria, 39005 Santander, Spain. E-mail: jorge.rodriguez@unican.es

*Corresponding author email: sanudola@unican.es 


\begin{abstract}
Blowing snow or sand transport generates serious problems such as transport infrastructures buried under snow or sand in many parts of the world. Some of the most important problems that snow and sand storms can cause include drivers getting trapped on the roads, traffic being held up indefinitely, accidents occurring and populations being isolated. Snow fences provide a solution to this problem as they can hold back the snow, preventing displacement and wind-induced drifting. In this way, they reduce these problems on transport infrastructures and improve visibility, providing safer driving conditions. In this review, a classification is proposed of snow fences based on three basic types: earth, structural and living snow fences. Among the structural ones, non-porous and porous snow fences are distinguished. The different possibilities in terms of the placement of snow fences are also analyzed. Finally, different types of snow fences have been compared under design, construction and operation criteria. This review can provide initial guidelines for technicians to choose the best snow fence for blizzard conditions.
\end{abstract}

Keywords: snow fence; blizzard; transport infrastructures; porosity. 


\section{Blizzard}

Blizzards are important and frequent winter effects caused by the combination of snow and strong winds (Gordon and Taylor, 2009a). Strong winds not only interact with snow, causing blizzards; but they can also pick up and transport sand or any other light particles such as dust or ash. Snow occurs in cold climates while sand transport creates problems in desert areas (Bofah and Al-Hinai, 1986; Zhao et al., 2008). This paper is mainly focused on snow fences.

Taking the snow transported by blizzard as a reference, there are three different kinds of movements:

- Surface creep: this takes place when particles are too heavy or wind speed too low. The forces exerted by the fluid are only capable of sliding or rolling particles around the point of contact with the surface. The dragged particles are the smallest proportion of the total transported (Box, 2001).

- Saltation: this movement occurs with those particles light enough to be separated from the surface but too heavy to remain suspended in the air or when the wind speed is not enough to keep them in the air. These particles bounce intermittently throughout the mantle of snow, sometimes liberating other particles on impact with the surface (Box, 2001). In each jump, particles describe a parabolic trajectory (Kobayashi, 1972) with a maximum height which depends on wind speed, but which rarely exceeds $10 \mathrm{~cm}$ in height. Most of the saltation particles are in the first $5 \mathrm{~cm}$ over the surface with speeds lower than 
20m/s (Box, 2001). The particles with lower density reach a higher height in the saltation movement, following a power law (Gordon et al., 2009b). Moreover, the average saltation height and length increase exponentially with friction velocity between wind and particle, because friction velocity influences the wind speed profile (Zhang and Huang, 2008).

- Suspension: this is also known as turbulent diffusion and it affects mainly very small particles $(\leq 100 \mu \mathrm{m}$ in air). The turbulent diffusion cannot take place until saltation phenomenon has arisen and the air velocity exceeds the threshold velocity for suspension. The suspended particles undergo turbulent buoyancy forces that overcome gravitational ones. They remain suspended in the turbulent flow until the air velocity decreases and they are deposited on the surface. The velocity of the suspended particles at a given height is close to the average wind speed at that height. The concentration of suspended particles reaches a maximum just above the saltation layer and decreases with increase in height at a rate that depends on wind speed and particle size (Box, 2001).

\section{Snow fences as a solution}

Different types of barriers or fences are used for different applications. Some of the most important are: barriers against snow avalanche (Gubler, 1988), rock fall barriers (Castro et al., 2009), windbreak barriers (El-Flah, 2009), noise barriers (Marrades, 2008), containment vehicles or crash barriers (Macek and Měšt'anová, 2009) and snow fences. Among them, the latter are used to confront the effects of blizzards. 
Snow fences are defined as a device to manage and retain blown particles in their upwind and/or downwind area. The main objective of this system is to reduce snow or sand deposits in a certain area, locating these accumulations in controlled areas where they do not interfere with other uses.

Snow fence design provides a solution to blizzard problems in a specific area. Therefore, after analysing the problem to be solved, it is necessary to delimit clearly and precisely the objectives set out for these barriers. Some of the principal objectives of the snow fences are:

- Protection of transport infrastructure: protect roads or railway lines from blizzard action (Baker and Williams, 1991; Tabler, 1991; Tabler, 1994; Daigneault, 2000; Iowa Department of Transportation, 2005; Tabler, 2005; Tabler and Meena, 2007; Castro-Fresno et al., 2008; Zech et al., 2009).

- Protection of populations: hold snow or sand outside the populated areas. This objective can improve living conditions in places with frequent blizzard problems (Outcalt et al., 1975; Shitara, 1979; Zhao et al., 2008).

- Livestock and agricultural plantations: reduce the impact of the blizzard on these outdoor production activities (Shaw, 1988; Zhao et al., 2008).

- Aquifer recharge: store snow in a certain area where the permeability lets this snow melt later and infiltrate into the ground (Sturges, 1992).

- Protection against blizzard erosion: prevent the loss of vegetation and soil erosion (Corneli and Gabriels, 2005), as well as protecting infrastructures, buildings and monuments. 
Snow fences are mainly used to protect transport infrastructures, producing a substantial improvement in safety and visibility. In this case, they even extend the life span of the road by preventing the erosion associated with blizzard action. As a result, snow fences are an important element in the decreasing number of road accidents in mountain roads and cold regions (Tabler and Meena, 2007).

Snow fences have been validated as an alternative to mechanical systems for the collection of snow in a large number of studies (Wangstrom, 1989; Tabler, 1991; Tabler, 1994; Tabler, 2005). Large amounts of money are invested each year by governments in guaranteeing safety of transport infrastructures in winter, mainly using mechanical systems. This amount may be ostensibly reduced using snow fences or other protective devices: landscaping or terrain modifications (Baker and Williams, 1991) and three-dimensional rough elements such as manmade obstacles for snow retention (Tabler, 2006).

Snow fences can fulfil their objectives thanks to three main functions that may be combined or used separately:

- Storage: snow fences store blizzard particles upwind and downwind depending on their porosity. Several studies prove that the barriers with $50 \%$ porosity have greater storage capacity (Tabler, 1991; Tabler, 1994; Naaim-Bouvet, 2001; Cheol-Woo and Sang-Joo, 2003; Tabler, 2005). Under 50\%, snow fences of $30 \%$ porosity have the highest Threshold velocity, prompting a good shelter effect for holding wind-blown particles (Sang-Joo, 2001). 
- Displacement: snow fences are able to transfer the snow deposit to the leeward area leaving a free space on the downwind side. This free space is enough to improve driving conditions and safety on transport infrastructures. Non-porous snow fences have lower storage capacity but they can displace the particles to a certain distance depending on the height of the barrier.

- Windswept: snow fences with a bottom gap achieve a cleaning effect on the downwind side, removing sand or snow deposits by concentrating the wind action on the surface. Increasing the height of the bottom gap improves the effectiveness of windswept (Naaim-Bouvet, 2001).

Snow fence performance depends on three basic parameters: porosity, height and snow fence bottom gap (Naruse, 1982; Tabler, 1991; Tabler, 1994; Tabler, 2005). Furthermore, the angle between snow fences and wind direction is a decisive parameter in the placement of the barriers. According to the cases studied, the best option is to arrange snow fences perpendicular to the direction of wind (Takeuchi et al., 2001). If this is not possible, the maximum angle between the snow fences and transport infrastructure should be $30^{\circ}$ (Tabler, 1991).

\section{Snow fence classification}

Snow fences can be classified according to various criteria (Tabler, 1994; Kelson, 1999; Tabler, 2005). In this paper, the proposed classification of snow fences is based on three basic categories: earth, structural and living snow fences. Concerning the category of structural snow fences, there are different options considering porosity, temporal use 
and material (Figure 1). The proposed classification is wide open and some other possible options could be discussed. However, its objective is to order the different possible types of snow fences. Moreover, apart from any qualitative classification, the quantitative parameters of design must be fixed for each application: porosity percentage, fence height and bottom gap height.

\subsection{Earth snow fences}

Earth snow fences are dust levees or little embankments formed by moving earth. An example of this type of barriers can be found in Colorado (USA) for the protection of railroads. They have small hollows on both sides of the embankment, increasing the storage capacity of these snow fences (Tabler, 1994).

Their performance is similar to solid or non-porous snow fences. This is because both types of snow fences work as a wall against blizzards. Particles in saltation and surface creep are captured by the barrier and they are stored in the upwind area. Furthermore, these snow fences cause an important effect of displacement helping the suspended particles enter a high-velocity flow over them. These particles are displaced from the snow fences and consequently away from the transport infrastructures too.

Their construction is simple and economical. It is only necessary to carry out a small earth movement near the transport infrastructure. This is an advantage if the snow fence is constructed at the same time as the infrastructure because then it is possible to use the same earthmoving machinery. 


\subsection{Living snow fences}

Living snow fences are vegetation barriers formed by one or more rows of trees, shrubs or other native vegetation with the necessary size and separation for snow control (Figure 2). An example of these barriers can be found in the U.S.A.. There are several living snow fence programs such as: the Laramie County Conservation District (1989), Iowa's Cooperative Snow Fence Program (2005) using structural snow fences and living snow fences, the New York State Department of Transportation (2008) and the Federal Highway Administration of the United States Department of Transportation (2009), among others.

The use of native species overrides the potential environmental impact posed by the introduction of foreign species, whose introduction is complicated and even negative for the habitat. In this kind of barriers, vegetation density influences the effectiveness, as porosity does in the structural snow fences.

Living snow fences have some advantages and disadvantages to consider for their implementation. The main advantages include the following: low cost of installation, practically zero maintenance, long-term duration, low impact and environmental integration improving the landscape. Taking into account that nowadays the environment is a vital factor in society, the use of living snow fences could be considered more suitable than others. In addition, living snow fences could turn out to be cheaper than structural snow fences (Daigneault, 2000). For these reasons, some 
authors consider living snow fences as a good choice for protection of the transport infrastructures (Kelson, 1999). The main disadvantage is that living snow fences begin to be useful only when the vegetation has grown (Shaw, 1988; Naaim-Bouvet and Mullenbach, 1998). Therefore, it is necessary to wait for a long time to see the development of the vegetation that reinforces the correct performance of the living snow fence.

The construction of these barriers requires knowledge of vegetation techniques. Moreover, it is necessary to know the type of native vegetation for the barrier placement. After vegetation is planted it must grow for a certain time until it reaches its functional size, which depends on the species. It is practically unnecessary to maintain these barriers, because their life span is longer than the other snow fences.

\subsection{Structural snow fences}

Structural snow fences are manmade using neither earth nor vegetation. The porosity is the most important design parameter for determining the efficiency of these snow fences (Dong et al., 2007). Depending on the percentage of porosity, the structural snow fences generate different kinds of snow deposits on both sides of the fence (Tabler, 1994; Tabler, 2005). This type of snow fences can be divided into two categories: non porous (or solid barriers) and porous snow fences. Apart from the consideration of the porosity, structural snow fences could be classified in terms of the time of use and material. 


\section{Classification of structural snow fences in terms of porosity:}

\section{- Non-Porous Structural Snow Fences}

Structural non-porous snow fences are defined as those barriers whose panels are solid and prevent the passing of blizzard through its structure. These barriers often have small holes in their structure, without ever exceeding $10 \%$ porosity, to allow the passage of the wind in order to reduce the stresses on them. Normally, they do not have a bottom gap but this is possible if the application justifies it and the sweeping effect is necessary (Figure 3) as a deflector fence (Cold Climate Technology Research Center, 2009). An example of this kind of snow fences without a bottom gap is the concrete barriers that are used in the railway line from Bilbao to La Robla (FEVE) near Arija (north of Burgos, Spain) to prevent blizzard particle deposits on the railway line.

Non-porous or solid snow fences produce similar deposits of snow on both sides of the barriers. These snow fences are unsuitable when the project aims to collect the maximum number of particles. The amount of snow stored is a third part of the porous snow fences with 50\% porosity (Tabler, 1994). Therefore, the use of non-porous snow fences is recommended only with little available space when porous snow fences lose efficiency. These snow fences function by displacing snow or sand particles carried by the blizzard to the other side of the transport infrastructure which they protect. Most of the particles are stored on the upwind side of the snow fence and they project the other particles to a given distance on the downwind side of it. This distance depends on the barrier height. 
In relation to the construction of this kind of barriers, the most used heights are in a range between 2 or $3 \mathrm{~m}$. Therefore, they can produce an important visual impact on the landscape depending mainly on the materials used for their construction.

\section{- Porous Structural Snow Fences}

Porous structural snow fences are defined as barriers whose structure is composed of tables, plates or any other type of element, ensuring the snow fence porosity is over $10 \%$ and consequently allowing the passage of most of the wind through them. Examples of this type of barriers are the Wyoming snow fences (Tabler, 1991) or the porous fences used in desert climates to control sand (Bofah and Al-Hinai, 1986).

Porous snow fences act directly on the blizzard flow and modify the wind profile. Thus, snow or sand deposits can change their shape depending on the design of the snow fence structure. This is why porous barriers are more effective than other barriers in the catchment and storage of blizzard particles.

Performance of porous snow fences depends on:

- Porosity percentage: the higher the porosity, the lower the reduction in wind speed downwind of the barrier, reducing the storage capacity of particles upwind of snow fences. $50 \%$ porosity has proved to be the most effective for greater storage of snow or sand particles on the windward face of snow fences (Bofah and Al-Hinai, 1986; Tabler, 1991; Tabler, 1994; Tabler, 2005). 
- Height: in this kind of barriers, height is fundamental because it modifies the wind profile (Tabler, 1994). So, the higher the fence is, the greater the ability to capture and store blizzard particles.

- Bottom gap: porous snow fences normally have a bottom gap. Some authors recommend that the bottom gap must be approximately $10 \%$ or $15 \%$ of the total snow fence height. Above this value, it loses storage capacity (Tabler, 1991; Tabler, 1994; Tabler, 2005), but it increases the sweeping effect in the area immediately downwind of snow fences.

Construction of porous snow fences does not require heavy machinery for earthmoving. They are constructed in pieces and their assembly is easier than the construction of non porous snow fences.

\section{Classification of structural snow fences in terms of the time of use:}

\section{- Fixed Structural Snow Fences}

Fixed structural snow fences are permanently installed in the chosen placement. For example, Swedish or Norwegian designs of snow fences have been widely used in northern Europe and the United States since 1885 (Tabler, 1994). As this model was the most used by the Wyoming Department of Transportation, it is considered the precursor of the Wyoming snow fences (Figure 4). Swedish or Norwegian snow fences have pieces of wood as a deflector at the top of them, while the Wyoming snow fences do not have these. This means that the storage capacity of the Swedish or Norwegian model is 
$70 \%$ of the storage capacity of the Wyoming barriers (Tabler, 2005). Considering the wide use of these two models, it could be stated that the most common snow fences throughout history have been fixed porous snow fences, made of wood.

\section{- Temporary Structural Snow Fences}

Temporary structural snow fences are those installed only for a limited time in the chosen placement. For example, they are used to protect ski resorts only during the winter or access roads to civil engineering works in cold climates only during the construction of the infrastructure.

This kind of snow fences ensure a fast and secure placement and subsequent removal after the end of the activity that needs to be protected from blizzard. Therefore, these barriers are usually flexible and lightweight structures made of plastics. Temporary snow fences made with polymer mesh tied to stakes are the most widely used. The stakes ensure the resistance to the wind and the mesh helps the passage of the blizzard through them modifying the wind profile depending on its porosity.

Occasionally, other barriers of wood or precast concrete could be used as temporary barriers, removing them in summer. Another solution for temporary applications is the use of fixed structural snow fences with a bottom hinge that enables them to fold down when they are not needed, minimising their visual impact on the environment in the absence of snow. 


\section{Classification of structural snow fences in terms of material:}

\section{- Wooden Structural Snow Fences}

Wooden structural snow fences are made mainly of wooden materials. Wooden snow fences were widely used for over a century worldwide. The life span of these snow fences depends on the biological degradation of wood (Noda et al., 2008). Normally, the wood used receives different treatments to prolong its structural integrity over time.

Swedish or Norwegian and Wyoming snow fences are the most common wood structural snow fences. However, there are other types of snow fences in this category. For example, buck and pole fences are formed by pieces of wood discarded in sawmills and vegetation piled on the ground without a predetermined order. Moreover, in this kind of snow fences other materials can be used in combination with wood, such as the use of steel poles supporting the snow fence (University of Manitoba, 2009).

- Metallic Structural Snow Fences

Metallic structural snow fences are made mainly of metal, normally steel. They are easy to assembly in pieces and the use of metal allows different and most complicated design geometries. These snow fences are porous and formed by plates, modifying the air flow characteristics of the blizzard. The steel used requires a specific treatment to protect it against the extreme climatic conditions, as happens with the wood used in the wooden structural snow fences. 
Metallic structural snow fences (Figure 4) are very efficient according to recent research using finite volume methods (Sakamoto et al., 2001a; Sakamoto et al., 2001b; Alhajraf, 2004; Castro-Fresno et al., 2008; García-Nieto et al., 2009) and wind tunnel experiments (Sakamoto et al., 2001a; Sakamoto et al., 2001b). The most important parameters that define the plates are the inclination angle with the ground and shape (Sakamoto et al., 2001a; García-Nieto et al., 2009). Depending on the aim of snow fences they may form different angles with the ground. The vibration of the plates increases with wind speed. This could be reduced by perforating the higher plate in the snow fence (Sakamoto et al., 2001b). For this reason, there are plates with (Sakamoto et al., 2001a; Sakamoto et al., 2001b) or without perforations (Castro-Fresno et al., 2008; García-Nieto et al., 2009).

\section{- Plastic Structural Snow Fences}

Plastic structural snow fences have low weight and low rigidity in their materials. Due to these characteristics, this type of barriers is used temporally, mainly in civil engineering works and ski slopes.

Plastic snow fences are worse than wooden snow fences according to the Department of Transportation of Ontario. This study was based in 13 quality characteristics related to the handling and durability of the barriers and 2 properties of materials among others. However, plastic structural snow fences achieve longer life span than wooden snow fences (Perchanok, 1991). 
- Concrete Structural Snow Fences

Concrete structural snow fences are mainly made of concrete, being non-porous snow fences. This type of barrier is the least common snow fence. However, they are used in some countries such as Spain. An example of these snow fences can be found in Arija (north of Burgos, Spain) to protect the railway from snow drift. Moreover, precast concrete elements are used only in one of the references consulted as a part of snow fences (Fuchs et al., 1991).

As a non-porous barrier, the concrete structural snow fences displace the snow to the downwind side of the transport infrastructure and their storage capacity is much smaller than porous snow fences.

This type of snow fences needs more time and heavy machinery for construction than other. Moreover, there can be some problems with concrete because of the weather conditions. Due to this, they must be carefully designed considering the use of concrete with specific additives for these extreme climates.

\section{Snow Fence placement}

Some of the variables that define snow fence placement are: snow quantity, wind speed and direction, topography, vegetation and other obstacles on the ground. 


\section{Snow quantity}

Snow quantity is the most important parameter in blizzards. The yearly snowfall in any placement influences the snow transport by wind. Moreover, it influences he design of the most suitable snow fence, especially the height. For example, in porous snow fences, this influence is demonstrated with graphs and equations that link snow transport and snow storage to the height of the snow fences (Tabler, 1991).

\section{Wind speed and direction}

Wind speed and direction are two of the most important parameters in blizzard. They directly influence the number of particles transported by blizzards and thus the place and shape of the sedimentation. Wind speed and direction also influence the fall of snow particles. The greater the wind speed, the faster the falling speed in that direction (Gordon et al., 2009b).

Snow transport by blizzards will depend on the surface size that is blown by the wind. This area is known as fetch (Tabler, 1991; Tabler, 1994). From this surface, the wind can take the snow and move it to the sedimentation area that may include a transport infrastructure. This behaviour can be changed if there are natural of artificial obstacles in the path of the blizzard; such as for example snow fences.

\section{Topography}

Ground characteristics decisively influence wind profile (MacDonald et al., 2009) and therefore the operation of the snow fences placed close to the transport infrastructures to be protected., The topography where the transport infrastructure is placed is varied and 
often presents some difficulties which complicate the placement of the snow fences. Four main types of situations can be distinguished: flat terrain, road cutting or trench, embankment and mid-slope (Figure 5).

a. Flat terrain (Figure 5.a): It is the most favourable topographic setting for the proper functioning of any snow fence. The main condition is that the snow fences must be placed mainatining the necessary distance in order to guarantee their proper functioning without any constraints.

b. Road cutting or trench (Figure 5.b): This situation of the transport infrastructure is perhaps the most complicated for the placement of snow fences. The influence area of the snow fence is very small due to topographical constrictions. Not all snow fences are suitable for this topography. When the trench is wide and the blizzard reaches the infrastructure, porous snow fences with bottom gap are the best option to avoid the sedimentation on the road. However, if the slopes are high the blizzard might not penetrate but the snow or sand can be collected and deposited directly on the transport infrastructure. In this case, non-porous snow fences are very useful to stop the sediments before they reach the infrastructure (Tabler, 1994).

c. Embankment (Figure 5.c): This can be considered the second most favourable case for the establishment of snow fences if the embankment slopes are not too high and its height is not excessive. The most widely used barriers in this case are porous snow fences with bottom gap which must be placed very close to the infrastructure to protect it. In some cases, if the banks have a considerable height, they could act as earth snow fences storing the particles of the blizzard. 
d. Mid-slope (Figure 5.d): This configuration is a mix of trench and embankment and depending on the wind direction the effect of one of them will be predominant, conditioning the selection of the snow fences.

\section{Vegetation}

The existence of vegetation is also a factor which alters the effects of the blizzard. It is necessary to be aware of the type, height and density of vegetation in the area to predict its influence on the wind profile and sedimentation (MacDonald et al., 2009). Vegetation reduces soil erosion and protects soil from the direct action of wind. With a suitable design and control, the vegetation could itself work as a living snow fence. On the other hand, high vegetation could reduce the sweeping effect caused by the bottom gap of some porous snow fences.

\section{Other obstacles}

Apart from the natural obstacles (topography and vegetation), there are several man made obstacles on the ground that could influence on the blizzard. These obstacles are mainly safety barriers and buildings. In general, safety barriers should be removed from the roads in places where the snow fences will be located because they could have a negative effect, storing blizzard particles on the highway and decreasing the safety during the winter. Furthermore, the influence of the buildings in the wind profile is very important. They could act as snow fences themselves and completely change the direction and speed of the wind in the surroundings. For this reason their present and future location must be taken into account in the snow fence emplacements. 


\section{Comparison of Snow Fences}

\subsection{Comparison criteria}

In this paper, snow fences are compared in terms of the following criteria: design, construction and operation. The comparison among the types of snow fences will be done through ranking tables according to the three criteria chosen. Thus, the numbers of the tables show a preference in the choice of the snow fences. Therefore, the best barrier according to each criterion will receive one point (first position), while the second will receive two (second position), and so on until the last (last position). Following this methodology, the barrier that receives fewest points in each table will be considered the most appropriate in comparison with the others. Of course, this comparison does not aim to be categorical because the selection of the most suitable snow fence depends on the local conditions for each specific application and the experience of the specialist in charge.

\section{Criteria}

- Design

To fulfil the objectives and ensure the necessary functions of a snow fence, it is essential to know the specific elements used in its design, as well as the placement parameters. These additional elements are: the suitability and quality of the materials used, number of components, necessary knowledge and complexity or simplicity of the 
total design. Each snow fence obtains a position depending on these elements in comparison with the others, the best one being the snow fence with the simplest design.

\section{- Construction}

For the construction of a snow fence, it is necessary to consider three main parameters: manufacturing, installation and economy. A continuous, industrial manufacturing process ensures a quicker and more efficient construction. Concerning the installation, each type of snow fence needs different machinery for its construction. Manufacture and installation both influence the cost of any snow fence, but they are not the only parameters that define the final expense of the snow fence construction. Accordingly, the best snow fence in the comparison is the one with the easiest construction process (direct manufacture, easy installation and suitable cost).

- Operation

After design and construction, snow fences must be monitored and maintained to ensure the maximum life span. There are snow fences with low maintenance while others are expensive due to the different materials and components. The life span depends directly on their design and the construction on site. The best snow fence type in this category will be the one with least maintenance and longest life span.

\subsection{Comparing earth, living and structural Snow Fences}

From the point of view of design, the easiest barrier of the three basic types of snow fences may be the structural snow fences. Despite the different materials and large number of elements, they are designed following defined and well-known guidelines and there are many studies and a lot of experience related to their use. The earth snow 
fence could be the second easiest type. This type only needs the use of one material and it does not require complex knowledge for its design. Finally, living snow fences could be considered to be the most complicated barriers to design because they require greater knowledge about native vegetation and about the different conditions of growth, functionality and porosity of each species.

Considering the construction process, the most appropriate basic type could be the structural snow fence because its manufacture and installation correspond to a totally controlled industrial process. The manufacturing process is continuous and installation is normally quick and easy. On the other hand, living snow fences are more complicated because they must be designed and made by botanic specialists, who are not experts in infrastructure construction. Moreover, they need a lot of time for the vegetation growth and to provide correct performance. Finally, earth snow fences are the least suitable barriers taking into account their construction process, as they require heavy machinery, equipment and a lot of space which could make their installation complicated, especially during the infrastructure working.

Taking into account the operation of the snow fences, the most suitable barrier could be the earth snow fence, always assuming that they are well designed and constructed with compaction and vegetation cover to avoid the erosion. The second best option could be the living snow fences because their maintenance is reduced to the monitoring of the vegetation development. Finally, structural snow fences could be considered the least appropriate according to the operating parameters because they have many elements to maintain and their life span is less than earth or living snow fences. 
All these arguments lead to the Table 1 where all the positions are reflected. Adding the position in each criterion and considering the total, the most suitable snow fences are structural ones, followed by earth and living snow fences.

\subsection{Comparison among the various types of structural Snow Fences}

\section{Comparison between non-porous and porous snow fences}

From the design point of view, the most suitable structural snow fences in terms of porosity could be the non-porous barriers. This is because they have a smaller number of components and their design is simple. On the other hand, the design of the porous snow fences is the most complicated because their function could more complete and they imply the study of more variables.

However, the construction of the porous snow fences could be easier and cheaper than non-porous. This is because of their continuous manufacturing process, which means there is more experience with them. Moreover, non-porous barriers need heavy machinery to move their pieces or to prepare them.

Taking into account the operation, porous snow fences would require less maintenance which is also faster than in the case of non-porous barriers. If a non-porous barrier has a defect or any problem, the solution could be very complicated, even including the change of the complete snow fence. However, in a porous snow fence it is only necessary to change the failed element, keeping the remaining pieces of snow fence. 
Therefore, considering the score of the total column in Table 2, the most appropriate barrier in terms of porosity is the porous snow fence.

\section{Comparison between fixed and temporary snow fences}

From the design point of view, fixed snow fences could be considered easier than the temporary ones because they do not require the design of their elements in order to be easily assembled and disassembled.

Nevertheless, temporary snow fences could be the easiest and cheapest barriers to construct. The installation of temporary snow fences is fast and easy because it is not necessary to use heavy machinery and manpower. Therefore, this type of barrier is cheaper than the others because it takes less time and resources to assemble.

For the operation, fixed snow fences could be the best option. They are made of more rigid materials with higher resistance and better anchorages than those used in the temporary snow fences. Moreover, when temporary snow fences fail, it is necessary to change all the snow fence because they are prepared to work as units, not to be repaired partially.

Analyzing the results in Table 3, the best barriers from the temporality point of view are fixed snow fences.

\section{Comparison of snow fences made of different materials}


Taking into account the materials design criteria, the most efficient snow fences would be metallic barriers. The reasons are the suitability of this material and the possibility of obtaining any kind of geometric design for a specific element of the barrier.

In second place, wood snow fences offer less suitability of the material with almost the same flexibility in the geometric design. In the third place, the plastic snow fences offer the lowest material competence of the four materials considered but maintain a high flexibility for the geometry of the different elements. Finally, the concrete barriers are the worst snow fences from this point of view. They need special additives to ensure the performance of the material under the extreme weather conditions, and from the geometric point of view this is the worst material to obtain complex geometries.

For construction, metallic barriers would be the most appropriate. They have a continuous manufacturing process. Their installation can always be done with the same machinery and well-known process. Moreover, due to these two reasons, they could be the cheapest from the construction point of view. In second place, wood snow fences would require more manpower to manufacture and install them. Depending on the country, the price and availability of material and manpower could vary and this argument could be more positive or negative. Next, the plastic snow fences, with the same advantages as the metallic ones, although with the drawback of the smaller resistance of the material compared with metal and wood that could cause breaks during the construction process. Finally, concrete barriers are the least suitable snow fences from the materials point of view because they are difficult to install in the majority of the placements where a snow fence is needed. In the case of using precast concrete 
barriers, the installation will be faster. However, the weight of these structures requires heavy machinery not easy to locate in the placement of the snow fence.

Regarding the material from the operation point of view, concrete barriers could be the most suitable option. Their life span could be unlimited and their maintenance insignificant, if they are correctly installed. Secondly, the metallic snow fences have a planned process of operation with periodical maintenance due to possible effects of the weather conditions on the different snow fences pieces. Next, wood barriers could have a shorter life span than the metallic snow fences. Moreover, it could be more difficult to repair a broken piece in a wood snow fence than in a metallic barrier. Finally, plastic barriers could have the shortest life span and the worst maintenance because of the effects of the weather conditions and the type of joints between the elements of the snow fence. For these reasons, normally they are used for temporary applications or only for certain parts of any other type of barrier.

Therefore, analyzing Table 4 and the total column, the most suitable barriers from a materials point of view are the metallic snow fences. This conclusion is limited by the scope of this analysis because the optimal for each application depends on the local conditions in each specific case, the available materials and the experience of the specialists in charge to give their own score based in each considered criterion. 


\section{Conclusions}

Snow fences have emerged as the most efficient and economical alternative for the protection of transport infrastructures against blizzards. They help reduce the negative consequences of drifting snow, sand or other materials carried by the wind.

The snow fence functions can be storage, displacement and windswept. Each snow fence can fulfil only one function or a combination of several of them at a time, depending on its design.

The proposed classification of snow fences is based on three basic categories: earth, structural and living snow fences. Among the structural snow fences, the main types are non-porous and porous snow fences. These two types could be classified in terms of temporality of the use of the snow fence and the main material used in it.

Some of the variables that define snow fence placement include: snow quantity, wind speed and direction, topography, vegetation and the presence of other obstacles on the ground.

The different types of snow fences have been compared under the criteria of design, construction and operation. From this comparison, it can be concluded that the most appropriate snow fences are structural porous fixed metallic snow fences. However, this methodology is limited and the final decision must depend on the specific conditions and the experience of the specialists in charge. 


\section{Acknowledgments}

The authors would like to thank SODERCAN and Malla Talud Cantabria Ltd. for their economic support in the research on snow fences. Moreover, the authors would like to express their gratitude to GITECO of the University of Cantabria for snow fence research support.

We would also like to thank the University of Oviedo, Spain, for its invaluable collaboration in this research. 


\section{References}

[1] Alhajraf, S. (2004). Computational fluid dynamic modelling of drifting particles at porous fences. Environmental Modelling \& Software 19 (2004) 163-170.

[2] Baker, H.A. and Williams, C. J. (1991). Research study of highway snowdrifting in Canada. Cold Regions Engineering, pp. 719-728.

[3] Bofah, K.K. and Al-Hinai, K.G. (1986). Field tests of porous fences in the regime of sand-laden wind. Journal of Wind Engineering and Industrial Aerodynamics 23 (C), pp. 309-319.

[4] Box, J.E. (2001). PhD. thesis: Surface water vapour exchanges on the Greenland ice sheet derived from automated weather station data.

[5] Castro-Fresno, D., López-Quijada, L., Sañudo-Fontaneda, L.A. and Mery-García, J.P. (2009). Revista de la Construcción. Pontificia Universidad Católica de Chile, Santiago. Vol. 8, No2, pp. 51-59.

[6] Castro-Fresno, D., del Coz Díaz, J.J., Rodríguez-Hernández, J., García Nieto, P.J., Sañudo-Fontaneda, L.A. and Álvarez Rabanal, F.P. (2008). Barrera protectora de las ventiscas. Spain. Number of invention patent P200803250. 2008-11-10.

[7] Cheol-Woo Park and Sang-Joon Lee (2003). Experimental study on surface pressure and flow structure around a triangular prism located behind a porous fence. Journal of Wind Engineering and Industrial Aerodynamics 91, pp. 165-184.

[8] Cold Climate Technology Research Center (2009). Wind \& Snowdrift around structures and infrastructure.

http://www.kaldtklima.net/sites/default/files/uploaded-

files/images/sections/wind\&snowdrift/deflector_fence.jpg (21/07/2009). 
[9] Corneli, W. M. and Gabriels, D. (2005). Optimal windbreak design for winderosion control. Journal of Arid Environments 61 (2), pp. 315-332.

[10] Daigneault, W. (2000). A Comparison of the Economic Efficiency of Living and Artificial Snowfence Designs for Road Protection. Western Journal of Applied Forestry 15 (2), pp. 70-74.

[11] Dong, Z., Luo, W., Qiang, J. and Wang, H. (2007). A wind tunnel simulation of the main velocity behind field upright porous fences. Agricultural and Forest Meteorology 146, pp. 82-93.

[12] El-Flah, A.H. (2009). The use of various wind barriers in controlling wind erosion in northwestern parts of Egypt. Journal of Applied Sciences Research 5 (5), pp. 490-498.

[13] Federal Highway Administration (FHWA). United States Department of Transportation (2009). Wildlife Protection: Keeping it simple. "Living snow fences" benefit both wildlife and motorists. http://www.fhwa.dot.gov/environment/wildlifeprotection/index.cfm?fuseaction=h ome.viewPhotos\&articleID=47\#photo121 (21/07/2009).

[14] Fuchs, H., Arnold, R., Bartl, A.M. and Hufnagl, E. (1991). Use of industrial textiles in road construction - from textile-reinforced crash barriers to heated mats for public roads. Chemiefasern/Textilindustrie 41-93 (7), pp. T202-204.

[15] García Nieto, P. J., Del Coz Díaz, J.J., Castro-Fresno, D. and Ballester Muñoz, F. (2009). Numerical simulation of the performance of a snow fence with airfoil snow plates by FVM. Journal of Computational and Applied Mathematics. Article in press. 
[16] Gordon, M. and Taylor, P.A. (2009a). Measurements of blowing snow, Part I: Particle shape, size distribution, velocity, and number flux at Churchill, Manitoba, Canada. Cold Regions Science and Technology 55 (1), pp. 63-74.

[17] Gordon, M., Savelyev, S. and Taylor, P.A. (2009b). Measurements of blowing snow, Part II: Mass and number density profiles and saltation height at Franklin Bay, NWT, Canada. Cold Regions Science and Technology 55 (1), pp. 75-85.

[18] Gubler, H. (1988). Permanent and temporary avalanche protection measures for tourist facilities. Int Seilbahn Rundsch, pp. 27-28.

[19] Iowa Department of Transportation. (2005). Iowa's Cooperative Snow Fence Program.

[20] Kelson, A.R. (1999). Economics of Living Snow Fences in the Intermountain West. Western Journal of Applied Forestry 14 (3), pp. 132-136.

[21] Kobayashi, D. (1972). Studies of snow transport in low-level drifting snow. Contrib. Inst. Low Temp. Sci. 24, pp. 1-58.

[22] Living Snow Fence Program. (1989). Laramie Conservation District.

[23] MacDonald, M.K., Pomeroy, J.W. and Pietroniro, A. (2009). Parameterizing redistribution and sublimation of blowing snow for hydrological models: Tests in a mountainous subarctic catchment. Hydrological Processes 23 (18), pp. 25702583.

[24] Macek, D. and Měšt’anová, D. (2009). Multi-criteria evaluation of crash barrier systems types. Baltic Journal of Road and Bridge Engineering 4 (3), pp. 108114+Ia+IIA+IIIA.

[25] Marrades, D.M.A. (2008). Road traffic noise-reducing devices. Carreteras 4 (157), pp. 124-133. 
[26] Naaim-Bouvet, F. and Mullenbach, P. (1998). Field experiments on 'living' snow fences. Annals of Glaciology 26, pp. 217-220.

[27] Naaim-Bouvet, F., Naaim, M. and Michaux, J.L. (2001). Snow fences on slopes at high wind speed: physical modelling in the CSTB cold wind tunnel. Natural Hazards and Earth System Sciences (2002) 3/4: 137-145.

[28] Naruse, R. (1982). The shape of snow drifts and distribution of wind speed around snow fences. Low temperature science. Series A: physical sciences, (Hokkaido University, Sapporo, Japan), pp. 65-73.

[29] New York State Department of Transportation (2008). Environmental. Living Snow Fence. $\quad$ https://www.nysdot.gov/ezine/repository/snow\%20fence\%20summer.jpg (21/07/2009).

[30] Noda Y., Mori, M., Kobayashi, H. and Maeda, N. (2008). Estimation of the service life of the connections of a wooden snow fence. Rinsan Shikenj Oha/Journal of the Hokkaido Forest Products Research Institute 22 (1), pp. 1-6.

[31] Outcalt, S. I., Goodwin, C., Weller, G. and Brown, J. (1975). Computer simulation of the snowmelt soil thermal regime at Barrow, Alaska. Water Resources Research 11(5), pp. 709-715.

[32] Perchanok, M. S. (1991). Snow fence operational and material testing. Cold Regions Engineering, pp. 708-718.

[33] Sakamoto, H., Moriya, M., Takai, K. and Obata, Y. (2001b). Development of a New Type Snow Fence with Airfoil Snow Plates to Prevent Blowing Snow Disasters: Part 2, Characteristics of the Aerodynamic Fluid Forces of Airfoil Snow Plates. Journal of Natural Disaster Science 23 (1), pp. 13-22. 
[34] Sakamoto, H., Moriya, M., Takai, K. and Obata, Y. (2001a). Development of a New Type Snow Fence with Airfoil Snow Plates to Prevent Blowing Snow Disasters: Part 1, Evaluation of performance by blowing snow simulation in a wind tunnel. Journal of Natural Disaster Science 23 (1), pp. 1-11.

[35] Sang-Joon Lee (2001). Wind tunnel observations about the shelter effect of porous fences on the sand particle movements. Atmospheric Environment $36 \mathrm{pp}$. 1453-1463.

[36] Shaw, D. L. (1988). The design and use of living snow fences in North America. Agriculture, Ecosystems and Environment 22-23 (C), pp. 351-362.

[37] Shitara, H. (1979). Distribution of snow accumulation observed in a small plain (Inawashire Lake, Mount Bandai). Science Reports, Tohoku University, Seventh Series, Geography 29 (2), pp. 169-184.

[38] Sturges, D. L. (1992). Streamflow and sediment transport responses to snow fencing a rangeland watershed. Water Resources Research 28 (5), pp. 1347-1356.

[39] Tabler, R.D. (1991). Snow Fence Guide. Strategic Highway Research Program, Washington D.C.

[40] Tabler, R.D. (1994). Design Guidelines for the Control of Blowing and Drifting Snow. Strategic Highway Research Program, Washington D.C.

[41] Tabler, R.D. (2005). Controlling Blowing Snow with Snow Fences. How to control blowing and drifting snow with snow fences and road design. Government Engineering, July-August 2005, pp. 30-32.

[42] Tabler, R.D. (2006). Three-Dimensional Roughness Elements for Snow Retention. Wyoming Department of Transportation, Cheyenne. 
[43] Tabler, R.D. and Meena, J.A. (2007). Effects of Snow Fences on Crashes and Road Closures: A-34 Year Study on Wyoming Interstate-80. 13th International Conference on Cold Regions Engineering, pp 74.

[44] Takeuchi, Y., Kobayashi, S., Sato, T., Izumi, K., Kosugi, K. and Xin, W. (2001). The effect of wind direction on drift control by snow fences. Annals of Glaciology 32, pp. 159-162.

[45] University of Manitoba (2009). Natural Resources Institute. http://www.umanitoba.ca/institutes/natural_resources/gallery/canada/nunavut/lgnu navut4.jpg. (21/07/2009).

[46] Wangstrom, Per (1989). Collector snow fences in the Arctic. The Northern engineer 21 (1-2), pp. 13-19.

[47] Zech, W.C., MacDonald, J.S. and Clemet, T.P. (2009). Field evaluation of silt fence tieback systems at a highway construction site. Practice Periodical on Structural Design and Construction 14 (3), pp. 105-112.

[48] Zhang, J. and Huang, N. (2008). Simulation of snow drift and the effects of snow particles on wind. Modelling and Simulation in Engineering 2008, art. no. 408075 .

[49] Zhao, W., Hu, G., Zhang, Z. and He, Z. (2008). Shielding effect of oasisprotection systems composed of various forms of wind break on sand fixation in an arid region: A case study in the Hexi Corridor, northwest China. Ecological Engineering 33 (2008) 119-125. 
Journal of Cold Regions Engineering. Submitted January 24, 2011; accepted June 16, 2011; posted ahead of print June 18, 2011. doi:10.1061/(ASCE)CR.1943-5495.0000031

\section{Figures}

Figure 1. Snow fence classification.

Figure 2. a) Living snow fence made up of shrub rows. b) Living snow fence made up of a single row of trees.

Figure 3. a) Solid or non-porous snow fence made of wood with bottom gap. b) Solid or non-porous snow fence made of concrete with holes in it and without bottom gap.

Figure 4. a) Wyoming Snow Fence. b) Porous structural Metallic snow fences (Courtesy of Malla Talud Cantabria, S.L.) (Castro-Fresno et al., 2008).

Figure 5. Example of snow fences placed on: a) Flat terrain. b) Road cutting or trench. c) Embankment. d) Mid-slope. 
Journal of Cold Regions Engineering. Submitted January 24, 2011; accepted June 16, 2011; posted ahead of print June 18, 2011. doi:10.1061/(ASCE)CR.1943-5495.0000031

\section{Tables}

Table 1. Comparison of the three basic snow fence types based on design, construction and operation.

Table 2. Comparison of the structural snow fences in terms of their porosity using design, construction and operation criteria.

Table 3. Comparison of structural snow fences basis of its temporary installation using design, construction and operation criteria.

Table 4. Comparison of structural snow fences in terms of the materials used with design, construction and operation criteria. 


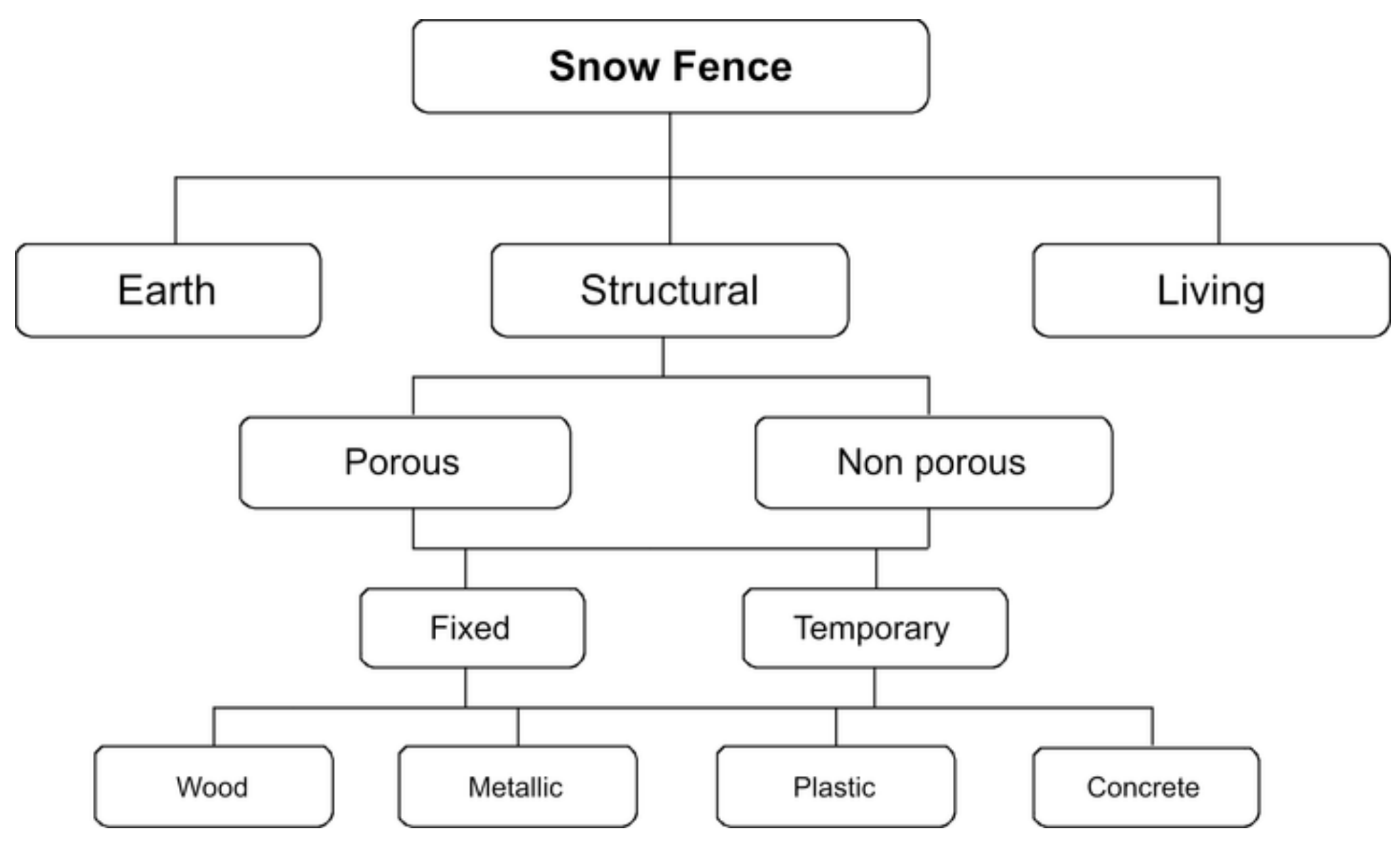


Journal of Cold Regions Engineering. Submitted January 24, 2011; accepted June 16, 2011; posted ahead of print June 18, 2011. doi:10.1061/(ASCE)CR.1943-5495.0000031
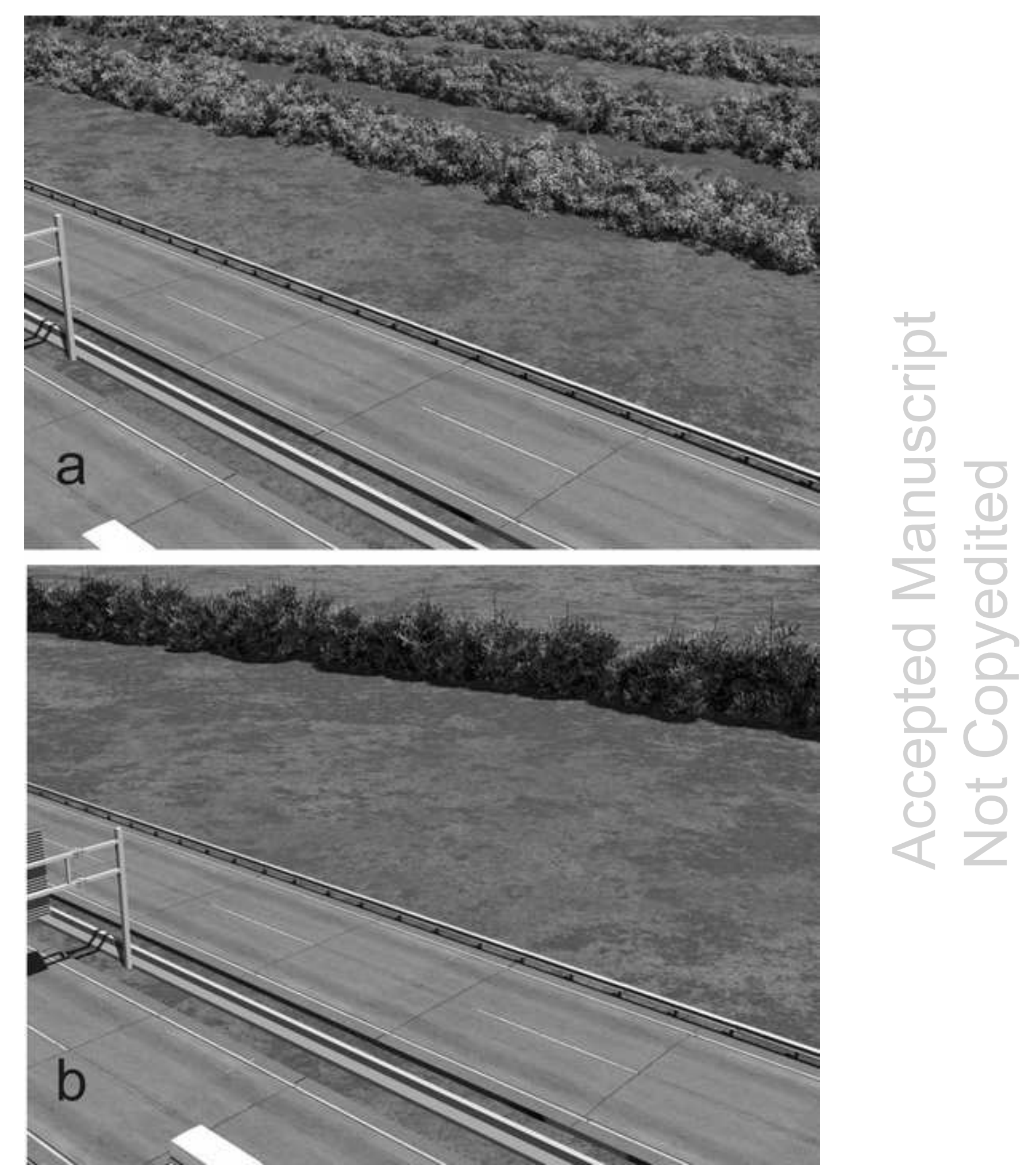
Figure 3

Journal of Cold Regions Engineering. Submitted January 24, 2011; accepted June 16, 2011; posted ahead of print June 18, 2011. doi:10.1061/(ASCE)CR.1943-5495.0000031

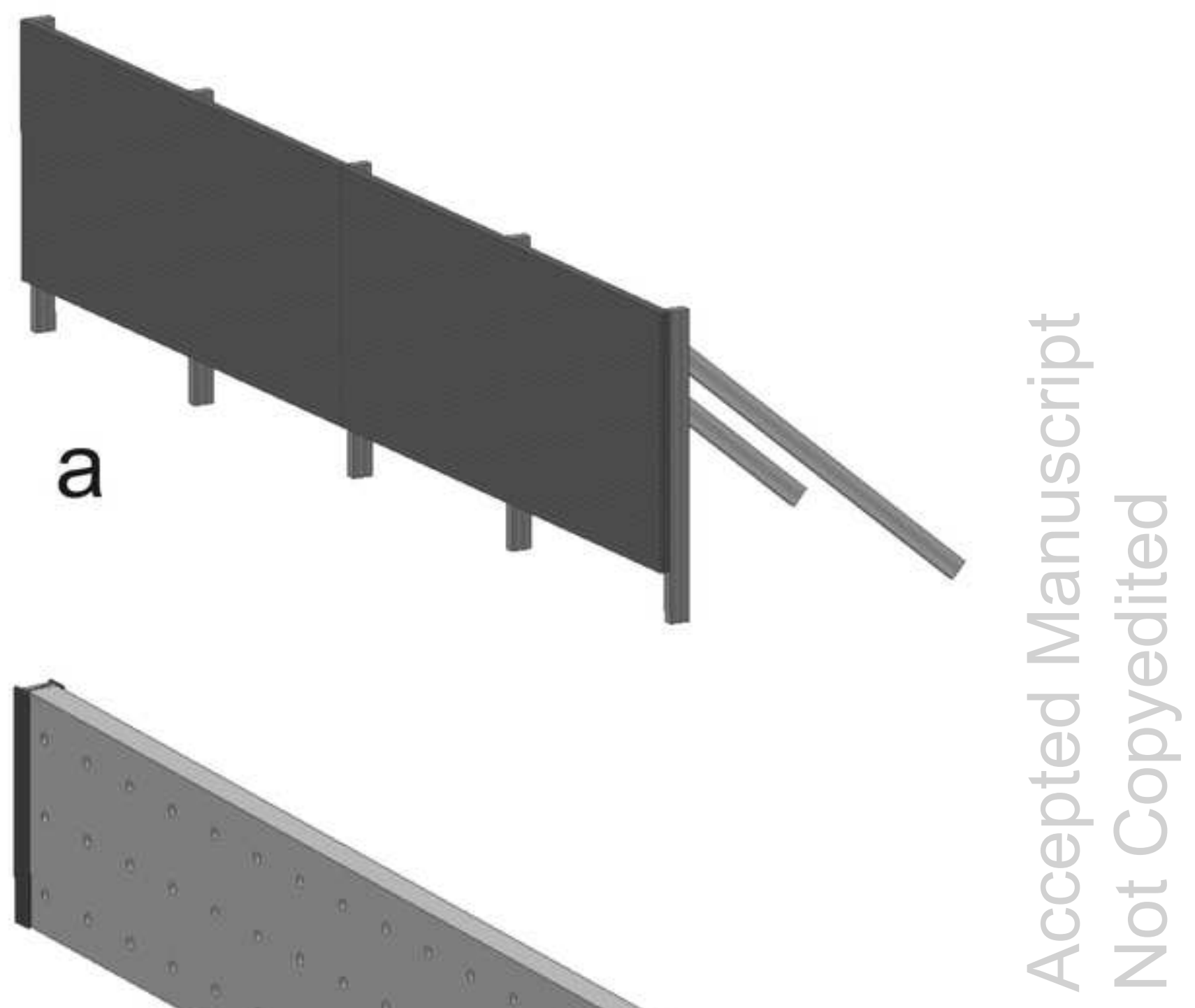


Journal of Cold Regions Engineering. Submitted January 24, 2011; accepted June 16, 2011; posted ahead of print June 18, 2011. doi:10.1061/(ASCE)CR.1943-5495.0000031

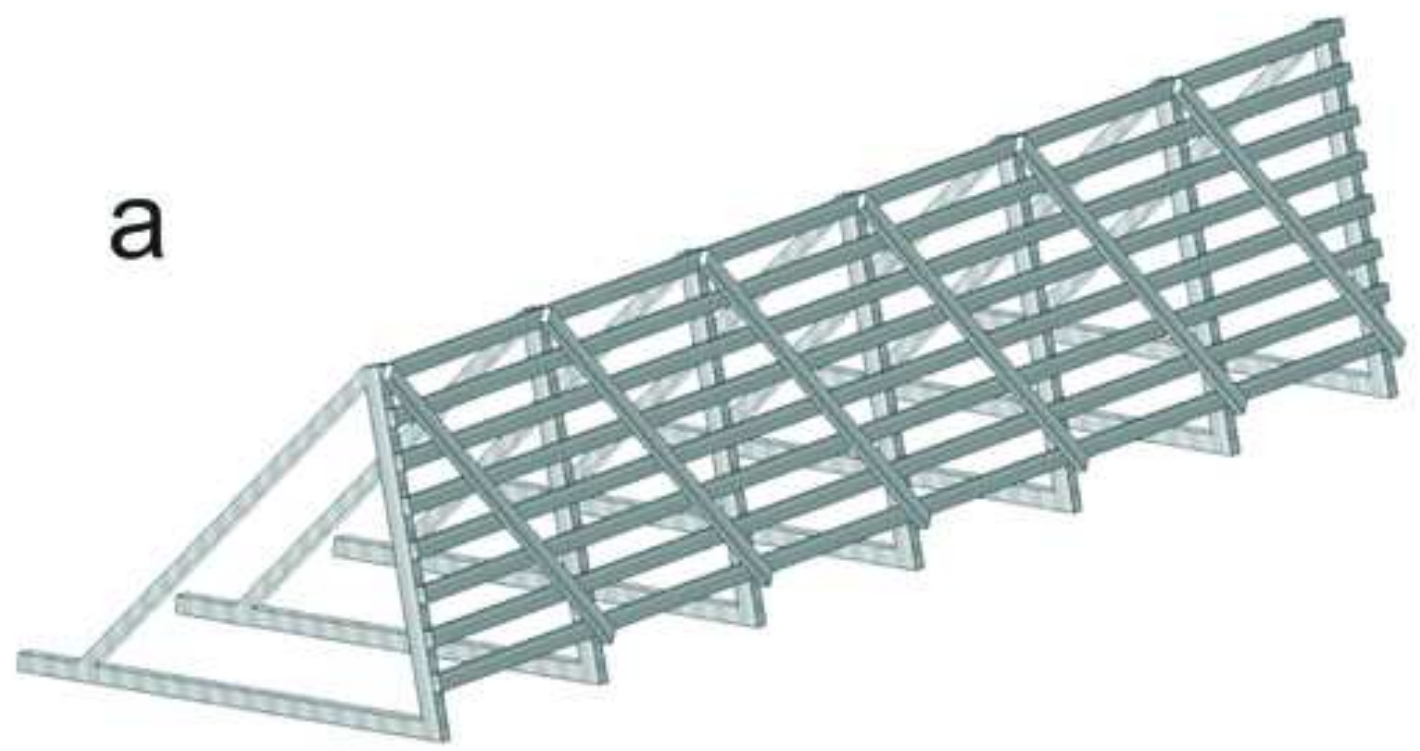

b
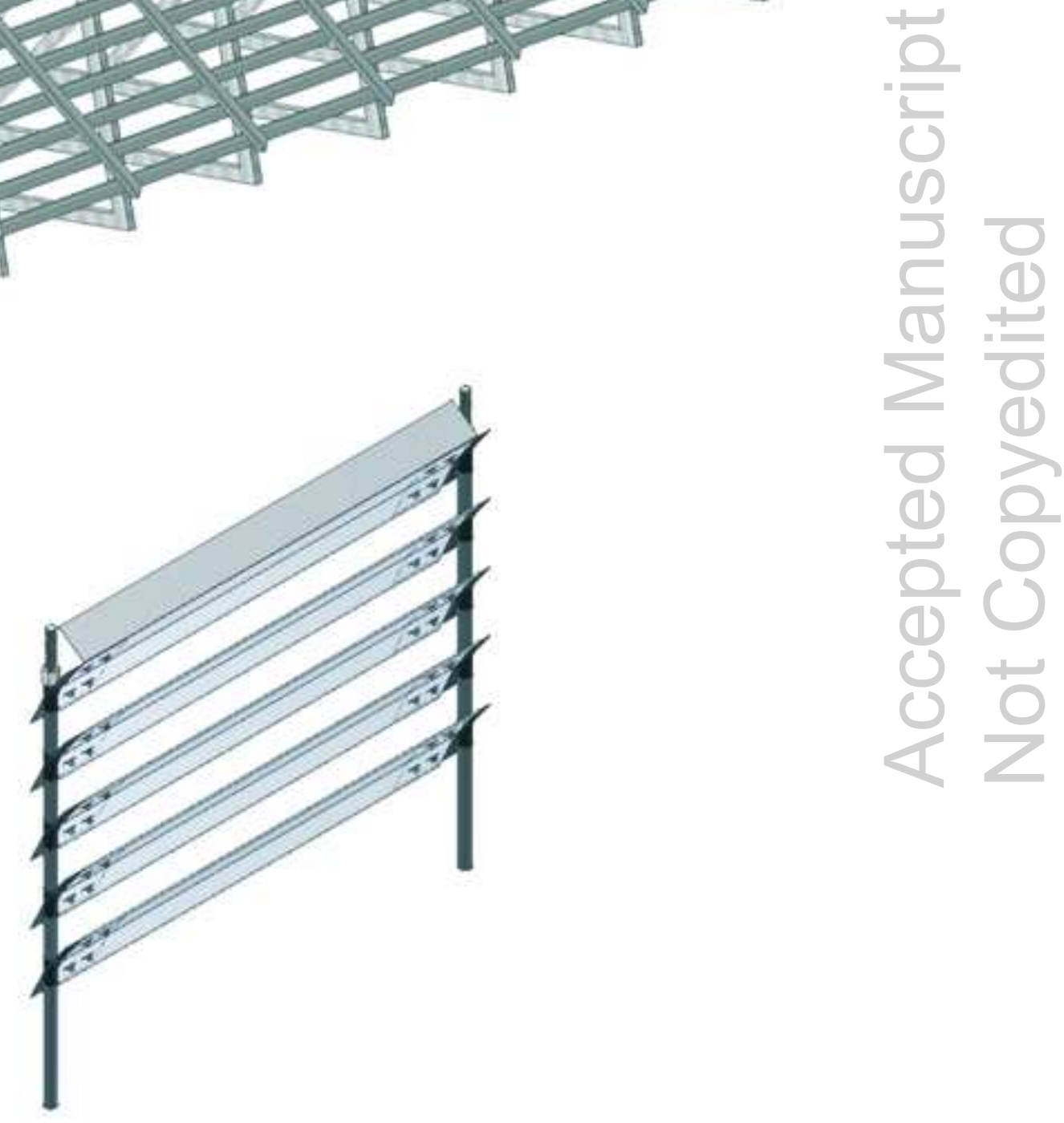

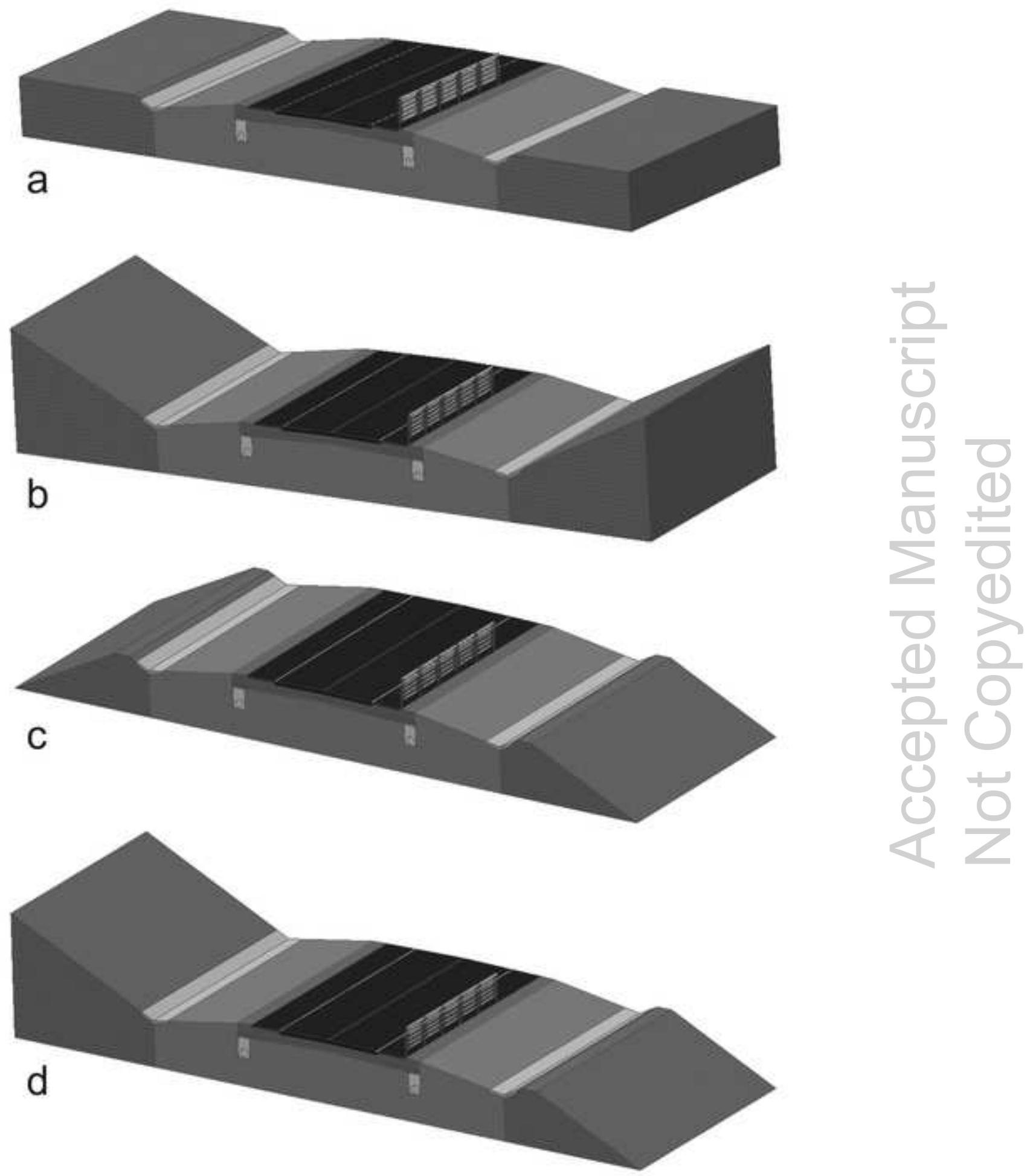
Table 1

\begin{tabular}{c|c|c|c|c}
\hline Snow fence basic type & Design & Construction & Operation & Total \\
\hline Earth & 2 & 3 & 1 & $\mathbf{6}$ \\
\hline Living & 3 & 2 & 2 & $\mathbf{7}$ \\
\hline Structural & 1 & 1 & 3 & $\mathbf{5}$ \\
\hline
\end{tabular}

"Each number means the preference order in the choice of the snow fence according to each criterion and the lowest total means the best general position.

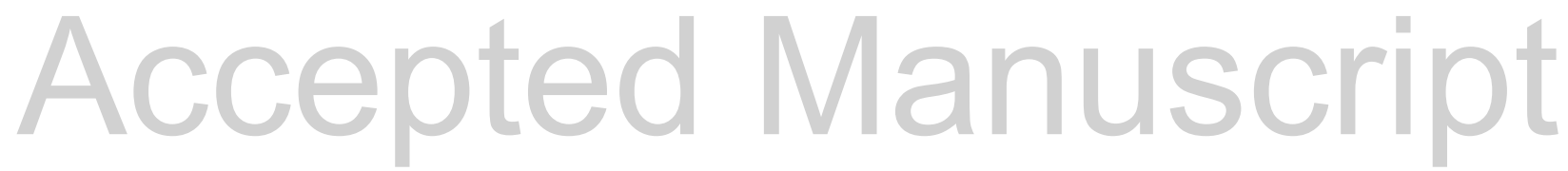
Not Copyedited 
Table 2

\begin{tabular}{c|c|c|c|c}
\hline $\begin{array}{c}\text { Structural snow } \\
\text { fences - Porosity }\end{array}$ & Design & Construction & Operation & Total \\
\hline Porous & 2 & 1 & 1 & $\mathbf{4}$ \\
\hline Non-porous & 1 & 2 & 2 & $\mathbf{5}$ \\
\hline
\end{tabular}

each criterion and the lowest total means the best general position..

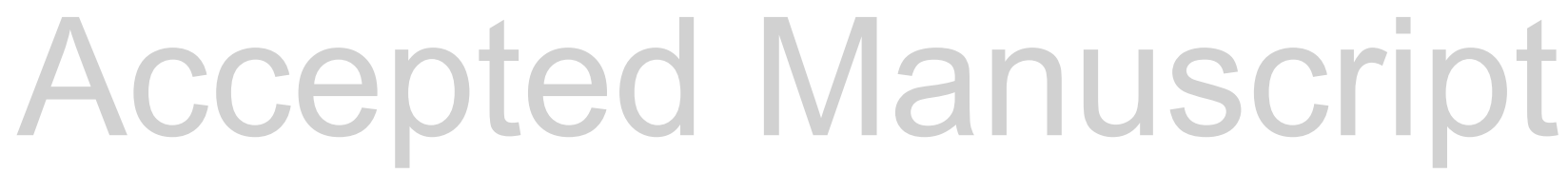

Not Copyedited 
Table 3

\begin{tabular}{|c|c|c|c|c|}
\hline $\begin{array}{c}\text { Structural snow } \\
\text { fences - Installation }\end{array}$ & Design & Construction & Operation & Total \\
\hline Fixed & 1 & 2 & 1 & 4 \\
\hline Temporality & 2 & 1 & 2 & 5 \\
\hline
\end{tabular}

each criterion and the lowest total means the best general position.

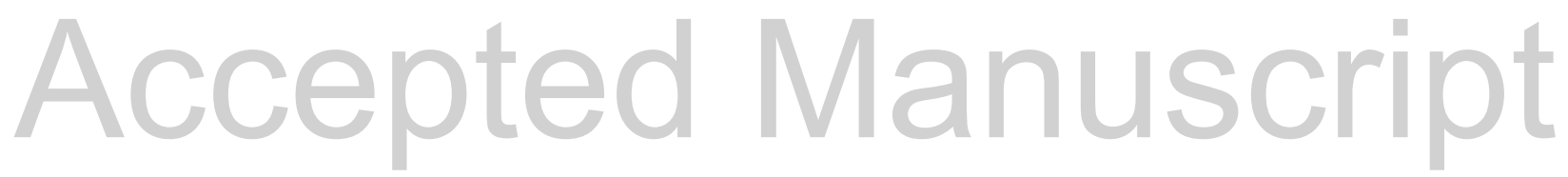

Not Copyedited 
Table 4

\begin{tabular}{c|c|c|c|c}
\hline $\begin{array}{c}\text { Structural snow } \\
\text { fences - Material }\end{array}$ & Design & Construction & Operation & Total \\
\hline Wooden & 2 & 2 & 3 & $\mathbf{7}$ \\
\hline Metallic & 1 & 1 & 2 & $\mathbf{4}$ \\
\hline Plastic & 3 & 3 & 4 & $\mathbf{1 0}$ \\
\hline Concrete & 4 & 4 & 1 & $\mathbf{9}$ \\
\hline
\end{tabular}

Each number means the preference order in the choice of the snow fence according to each criterion and the lowest total means the best general position. 